\title{
Correction to: Quantum colliding of nanoscale solitons in a domain wall of magnetic stripe domain
}

\author{
A. B. Shevchenko ${ }^{1}$ (D) M. Yu. Barabash ${ }^{2}$
}

Published online: 19 August 2019

c) King Abdulaziz City for Science and Technology 2019

\section{Correction to: Applied Nanoscience (2019) 9:595-599 https://doi.org/10.1007/s13204-018-0644-9}

The article Quantum colliding of nanoscale solitons in a domain wall of magnetic stripe domain, written by A. B. Shevchenko and M. Yu. Barabash, was originally published electronically on the publisher's internet portal (currently SpringerLink) on 26 February 2018 with open access. With the author(s)' decision to step back from Open Choice, the copyright of the article changed on 16 August 2019 to (C) King Abdulaziz City for Science and Technology 2019 and the article is forthwith distributed under the terms of copyright.

The original article has been corrected.

The original article can be found online at https://doi.org/10.1007/ s13204-018-0644-9.

M. Yu. Barabash

bashik_77@ukr.net

A. B. Shevchenko

andborshev@ukr.net

1 G.V. Kurdymov Institute of Metal Physics, National Academy of Science of Ukraine, 36 Vernadskogo pr., Kyiv-142 03680, Ukraine

2 Technical Centre, National Academy of Science of Ukraine, 13 Pokrovskya str, Kiev 04070, Ukraine 